\title{
Impactos da contenção dos preços de combustíveis no Brasil e opções de mecanismos de precificação
}

\author{
EDMAR LUIS FAGUNDES DE ALMEIDA \\ PATRICIA VARGAS DE OLIVEIRA \\ LUCIANO LOSEKANN"
}

\begin{abstract}
RESUMO: A Petrobrás foi severamente afetada pela política de preços de combustível do governo. Ao atender a crescente demanda de GLP, diesel e gasolina, cujos preços estavam abaixo de referência internacional, a empresa perdeu R 98.000 milhões dólares em renda, de 2011 a 2014. Em um período de altos investimentos devido a exploração do pré-sal, este perda aumentou a dívida da Petrobrás e deteriorou sua situação financeira. Se o alinhamento com o preço internacional não é politicamente viável, a experiência internacional sugere que se adote um fundo de estabilização como mecanismo de preços. Interferências políticas em sua gestão, no entanto, devem ser evitadas.

PALAVRAS-CHAVE: preços dos produtos de petróleo; a Petrobras; os mecanismos de fixação de preços; os fundos de estabilização.

ABSTRACT: Impact of fuel prices containment in Brazil and pricing mechanisms options. Petrobras was severely affected by the government's fuel pricing policy. By meeting the increasing demand of LPG, diesel and gasoline, whose prices were below international reference, the company has lost $\mathrm{R} \$ 98$ billion in income from 2011 to 2014. In a period of high investments due the exploration of the pre-salt, this loss raised Petrobras debt and deteriorated its financial situation. Should full alignment with the international price be not politically feasible, the international experience suggests adopting stabilization fund as proper pricing mechanism. Political interferences in its management, however, should be prevented.
\end{abstract}

KEYWORDS: oil products prices; Petrobras; pricing mechanisms; stabilization funds. JEL Classification: Q32; Q38; Q43.

\footnotetext{
* Respectivamente, Universidade Federal do Rio de Janeiro, Instituto de Economia, professor associado. E-mail edmar@ie.ufrj.br; Universidade Federal do Rio de Janeiro, Instituto de Economia, mestranda. E-mail patriciavsc.oliveira@gmail.com; Universidade Federal Fluminense, Faculdade de Economia, professor associado. E-maill: losekann@economia.uff.br. Submetido: 18/agosto/2014; Aprovado: 12/ setembro/2014.
} 


\section{INTRODUÇÃO}

Os últimos quatro anos foram marcados pela utilização dos preços de energia para combater a inflação no Brasil. Repetindo o que ocorreu em outros momentos da história brasileira, os efeitos setoriais dessa política foram bastante danosos.

No segmento de derivados de petróleo, o governo brasileiro tem influenciado os preços, que são livres desde o início dos anos 2000, através do controle acionário da Petrobras. Como a Petrobras detém a quase totalidade do refino e da importação de derivados, sua estratégia acaba definindo o preço de todo o mercado nacional. Adicionalmente, o governo federal concedeu reduções fiscais à gasolina e ao diesel visando conceder os reajustes de preços na refinaria sem repasse ao consumidor final entre 2011 e final de 2014 , período em que os preços internacionais do petróleo experimentaram níveis elevados.

A política de preços dos combustíveis orientada pelo controle da inflação causou grandes impactos econômicos para a Petrobras. A impossibilidade de repassar integralmente os preços internacionais para o consumidor implicou a renúncia de receitas pela Petrobras nos combustíveis que produz e vende no país. Adicionalmente, a empresa teve prejuízos nas importações de gasolina, diesel e GLP, vendidos abaixo do preço de compra no mercado internacional ${ }^{1}$.

Esses impactos econômicos negativos comprometem a capacidade de investimento da empresa, além de reduzir a atratividade dos investimentos privados no segmento downstream da indústria do petróleo no Brasil. Nesse sentido, é bastante clara a necessidade de se pensar uma nova política de preços de derivados para o país e avaliar quais as lições da experiência internacional para o caso brasileiro, no que se refere às políticas de precificação dos derivados.

A experiência internacional aponta diferentes abordagens para a determinação dos preços de derivados. Neste trabalho, foram analisados mercados em que os preços são totalmente livres e em que contam com fundos de estabilização. A partir das experiências estudadas são retiradas lições para uma opção de precificação para o Brasil.

\section{CONTROLE DOS PREÇOS DOS COMBUSTÍVEIS NO BRASIL}

\section{Política de precificação dos combustíveis}

A abertura econômica da década de 1990 deu os primeiros passos no sentido de liberalizar os preços de derivados de petróleo no Brasil. Nesse período, houve, além da abertura de capital da Petrobras, a liberalização de preços nas refinarias, postos revendedores, e fretes para determinados derivados, e foi dado novo tratamento ao capital privado no setor de petróleo (Colomer e Tavares, 2012). A Lei do Petróleo no

\footnotetext{
${ }^{1}$ Essa situação esteve vigente até outubro de 2014. A queda recente do preço internacional do petróleo motivada pelo crescimento da produção não convencional norte-americana, fez com que os preços domésticos dos derivados se tornassem mais elevados que os do mercado internacional.
} 
9.478 de 1997, que instituiu o Conselho Nacional de Política Energética (CNPE), e a Agência Nacional de Petróleo, Gás Natural e Biocombustíveis (ANP), previa gradual liberalização de preços com o fim dos subsídios para igualar os preços nacionais aos internacionais. Dessa forma, os preços foram totalmente liberalizados em 2002.

O preço final ao consumidor de gasolina, diesel e GLP tem como componente mais importante o preço de venda na refinaria. No caso do diesel e da gasolina os tributos são o segundo componente dos preços, seguidos das margens nas atividades de revenda e distribuição e do valor correspondente à participação do etanol na gasolina C ( $11 \%$ do preço) e do biodiesel no diesel (5\%). Com menor importância, os fretes representaram 2\% dos preços da gasolina e do diesel em 2013. Além do custo de produção do GLP, as margens de distribuição e de revenda tiveram peso significativo no preço final aos consumidores $(28 \%$ e $27 \%$, respectivamente), sendo os impostos os menos relevantes (17\%) (FECOMBUSTÍVEIS, 2014).

A composição dos preços dos três principais derivados de petróleo tratados neste trabalho pode ser ilustrada da seguinte forma (Figura 1):

Figura 1: Composição dos preços da gasolina, diesel e etanol (GLP)

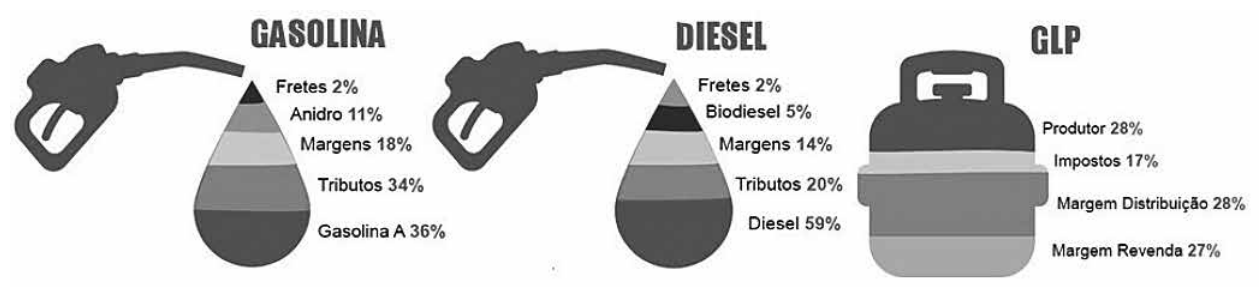

Fonte: FECOMBUSTÍVEIS (2014).

Dentre os impostos incidentes sobre esses derivados estão o Imposto sobre Circulação de Mercadoria e Serviço (ICMS), estadual; o PIS/PASEP e COFINS. Pode-se considerar também o Imposto sobre Importação, nulo desde 2001, e a alíquota da Contribuição de Intervenção de Domínio Econômico (CIDE). A CIDE é nula para o GLP desde 2004 e, para a gasolina e o diesel, foi reduzida em 2011 (Decreto 7.591) e se manteve zerada entre junho de 2012 (Decreto no 7.764) e início de 2015.

O mercado de derivados é livre desde 2002, mas, como a Petrobras domina todo o parque de refino nacional, a empresa tem a responsabilidade de facto de abastecer o mercado interno. A empresa determina os preços no mercado interno e tem praticado preços inferiores ao internacional, especialmente a partir de 2011. A política de preços da empresa segue os princípios e objetivos definidos pelo conselho de administração, cuja maioria representa o acionista controlador, a União.

Os parâmetros da metodologia de precificação são internos à empresa, cabendo ao conselho de administração avaliar a eficácia da política de preços. Enquanto o preço do GLP residencial não sofreu nenhum reajuste entre 2011 e 2014, os preços do diesel e da gasolina sofreram alguns reajustes na refinaria, mas continuaram aquém dos preços internacionais. Já o preço do GLP residencial sofreu apenas um reajuste ao final de 2014 (Quadro 1). 
Quadro 1: Reajustes de preços entre janeiro de 2011e setembro de 2014

\begin{tabular}{llccc}
\hline \multirow{2}{*}{ Ano } & \multirow{2}{*}{ Mês } & \multicolumn{3}{c}{ Reajuste } \\
\cline { 3 - 5 } 2011 & Novembro & - & Diesel & Gasolina A \\
\hline \multirow{2}{*}{2012} & Junho & - & $2 \%$ & $10 \%$ \\
\hline \multirow{2}{*}{2013} & Julho & - & $3,94 \%$ & $7,83 \%$ \\
& Janeiro & - & $6 \%$ & - \\
\hline \multirow{2}{*}{2014} & Março & - & $5,40 \%$ & $6,60 \%$ \\
& Novembro & - & $5 \%$ & - \\
\cline { 2 - 5 } & Novembro & - & $8 \%$ & $4 \%$ \\
\cline { 2 - 5 } & Dezembro & $15 \%$ & $3 \%$ & $5 \%$ \\
\hline
\end{tabular}

Fonte: Petrobras (2014).

Como ressaltado, os reajustes recentes de preços ocorreram paralelamente à redução dos impostos federais. O objetivo dessas medidas era evitar que os reajustes na refinaria fossem repassados ao consumidor final, evitando assim impactos inflacionários e os impactos políticos negativos dos reajustes.

\section{Mercados de gasolina, diesel e GLP}

Os mercados de gasolina e de diesel foram marcados por um forte crescimento da demanda os últimos cinco anos. A oferta doméstica de derivados não acompanhou o crescimento da demanda, o que resultou numa elevação da dependência externa (ver Gráficos 1 e 2). Segundo o Plano Estratégico - 2013 da Petrobras (2014), a previsão é de que o equilíbrio entre oferta e demanda de derivados no Brasil ocorra somente em $2020^{2}$.

\section{Gasolina}

O mercado de gasolina é marcado pela grande penetração dos veículos flex fuel que ocorreu no mercado brasileiro a partir de 2003. Essa mudança estrutural fez com que o desempenho da indústria do etanol se tornasse fator relevante para explicar a demanda por gasolina, além das tradicionais variáveis renda e preço (ANP, 2013).

Assim, após anos seguidos de baixo crescimento de vendas de gasolina C, em função do crescimento da produção e vendas de etanol no Brasil, o ano de 2010 marca a mudança de uma nova tendência de crescimento da demanda por gasolina. Essa demanda, que cresceu 17,5\% em 2010, 19\% em 2011 e $12 \%$ no ano seguinte, foi impulsionada tanto pelo aumento da frota de automóveis do ciclo Otto, quanto pelo mau desempenho da indústria de etanol a partir de 2010, resultando na elevação dos preços do etanol hidratado, principal concorrente da gasolina C.

\footnotetext{
${ }^{2}$ Essa previsão ainda contava com os investimentos da Petrobras nas refinarias Premium I e Premium, cujos projetos foram cancelados no início de 2015.
} 
O forte aumento da produção interna em 2010 foi incapaz de acompanhar a velocidade de expansão da demanda, sendo necessário elevar as importações para garantir o abastecimento interno (FECOMBUSTÍVEIS, 2013).

No ano de 2011, o contínuo aumento da demanda fez crescer as importações de gasolina. Essas importações crescentes se explicam também pelo fato da Petrobras não ter se preparado adequadamente para a produção deste combustível. De fato, o bom desempenho da produção de etanol em 2009 levou a empresa subestimar o crescimento da demanda de gasolina nos anos subsequentes. Por esta razão a empresa priorizou a produção de diesel na expansão do parque de refino. Assim, desde 2011 as importações superam as exportações de gasolina. Já em 2012 e 2013, as vendas continuam crescendo, mas com certo alívio nas importações em 2013 devido a melhorias de eficiência no refino da Petrobras e elevação do teor de etanol anidro na mistura de $20 \%$ para $25 \%$ em maio daquele ano (FECOMBUSTÍVEIS, 2013).

$\mathrm{O}$ volume de vendas de gasolina $\mathrm{A}$, bem como a produção e a exportação são apresentados no Gráfico 1.

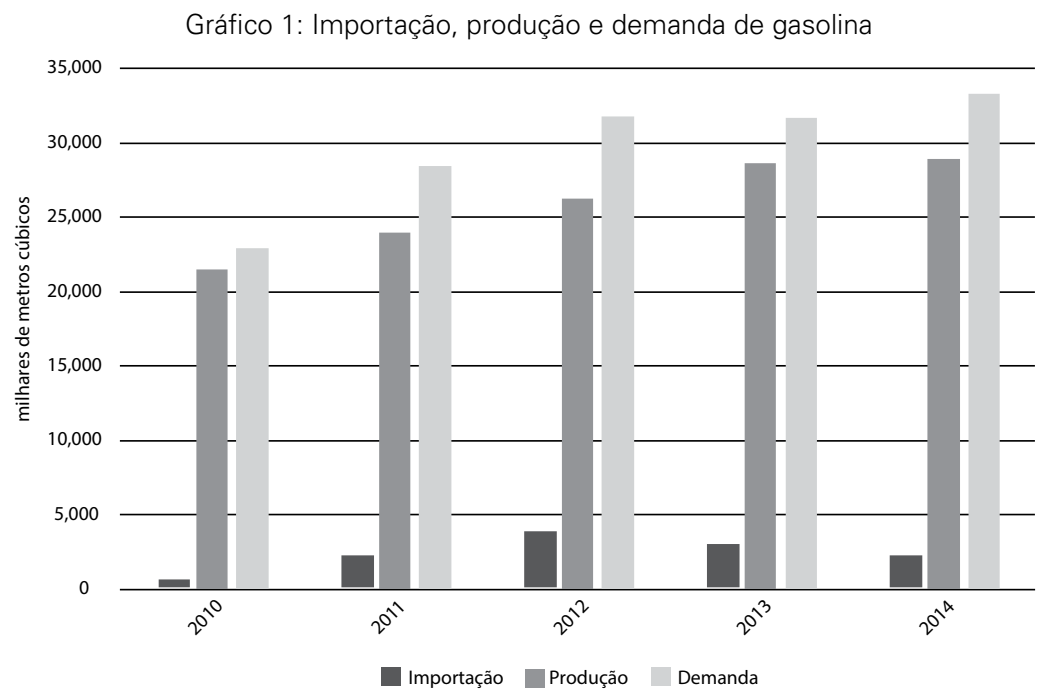

Fonte: ANP (2014).

\section{Diesel}

O crescimento do consumo de diesel foi superior ao crescimento do PIB desde 2010. O aumento da demanda teve impacto significativo na balança comercial. As importações vêm crescendo desde 2010 e atingiram patamar recorde em 2011 (9,3 bilhões de litros). Em 2012, os esforços de melhorar a eficiência nas unidades da Petrobras refletiram em uma redução de $15 \%$ das importações do derivado já em 2012 e também em 2013 (Gráfico 2). A Federação Nacional de Comércio de Combustíveis e Lubrificantes (FECOMBUSTÍVEIS, 2013) espera que brevemente as importações sejam ainda mais reduzidas à medida que as novas refinarias entrarem em funcionamento. 
Gráfico 2: Importação, produção e demanda de diesel

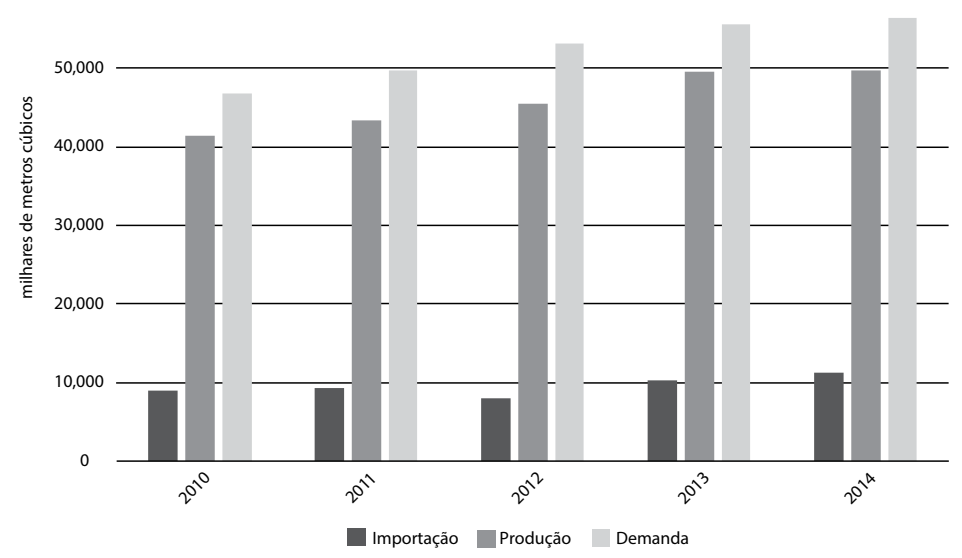

Fonte: ANP (2014)

\section{GLP}

No caso do GLP, o consumo vem perdendo fôlego ultimamente (Gráfico 3). O crescimento foi de 3,7\% em 2010 e se reduziu nos anos seguintes, especialmente devido ao baixo desempenho do PIB e à diminuição das refeições realizadas em casa, seu principal uso residencial. Ressalte-se que o combustível vem sendo substituído pelo gás natural, tanto no segmento comercial como no residencial (FECOMBUSTÍVEIS, 2013). Entretanto, apesar do baixo crescimento da demanda, o país é muito deficitário na produção de GLP. Neste sentido, a política de preços do GLP tem um impacto importante sobre a Petrobras.

Gráfico 3: Importação, produção e demanda de GLP

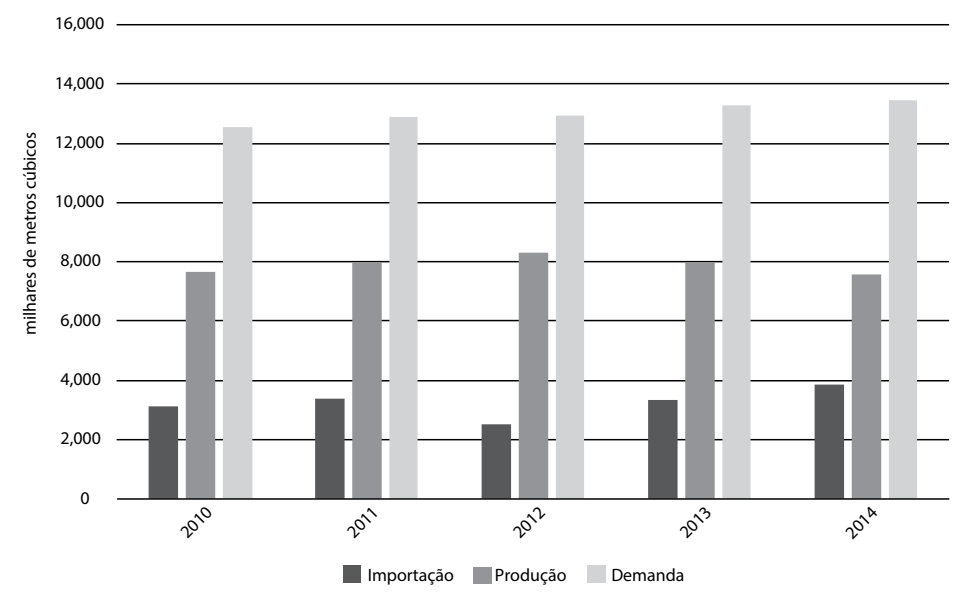

*agosto de 2014

Fonte: ANP (2014). 


\section{Comparação dos preços domésticos e internacionais}

Para comparar os preços domésticos com os internacionais foi considerado o preço interno de realização dos combustíveis (preço FOB na refinaria), o preço de referência internacional e o preço efetivamente pago com as importações. Os preços de realização dos três principais derivados foram obtidos de estatísticas do Ministério de Minas e Energia (MME, 2014), enquanto os preços internacionais de referência foram definidos com base nas cotações semanais de gasolina e de diesel no golfo norte-americano e do propano Mont Belvieu para o caso do GLP, obtidas da Energy Information Administration (EIA, 2014). A estimativa dos preços efetivamente pagos com importações de combustíveis foi feita a partir dos dados mensais de volume importado e de dispêndio FOB com importações provenientes da Secretaria de Comércio Exterior do Ministério do Desenvolvimento, Indústria e Comércio Exterior (SECEX/MIDIC, 2014). Os preços de referência e de importação são ajustados pelos custos de internação de cada derivado, definidos pelo MME, para obtenção do Preço Paridade Internacional.

Apesar de amplamente utilizados em estudos sobre alinhamentos de preços, os preços do mercado norte-americano nem sempre correspondem aos praticados nas importações da Petrobras. Nesse sentido, este trabalho se propõe a avaliar o impacto financeiro do diferencial de preços dos derivados na Petrobras a partir de duas perspectivas. A primeira delas diz respeito às perdas da empresa pela importação de combustíveis a preços superiores ao preço de realização praticado entre 2011 e 2014. Esse cálculo é feito a partir do preço médio real pago pelas importações e do volume importado. Outra influência negativa da política de preços na empresa é de receitas que poderiam ser auferidas pela empresa, caso vendesse os derivados aos preços internacionais. Nesse segundo caso, serão utilizados os preços de referência internacional, já que estes seriam o alvo caso houvesse uma política de alinhamento de preços no Brasil. Os resultados apresentados dizem respeito ao somatório das perdas entre 2011 e 2014.

Os gráficos a seguir apresentam a evolução dos preços dos três derivados no período de 2011 a 2014. No caso da gasolina A (Gráfico 4) pode-se perceber que a tendência ascendente dos preços de importação e de referência está acima da tendência dos preços de realização interno até novembro de 2014. Em termos absolutos, no início de 2011 os preços encontravam-se um pouco acima de $\mathrm{R} \$ 1,10$ por litro, não tão distante dos preços internos ( $\mathrm{R} \$ 1,024 / 1)$, o contrário do verificado em 2012, quando houve o maior "descolamento" dos preços, impulsionado pela variação cambial. No segundo semestre de 2014 os preços de referência passaram a decrescer, ficando abaixo do preço doméstico e de importação.

Situação semelhante ocorre no caso do diesel, com a diferença que este teve aumentos mais frequentes no período analisado. Como mostra a Gráfico 5, o maior diferencial entre os preços praticados domesticamente e de importação se deu no ano de 2012, especificamente de abril a junho, novembro e dezembro, em parte devido à variação cambial. A tendência ascendente dos preços internacionais do diesel durou até meados de 2014. No final de 2014, os preços de realização domés- 


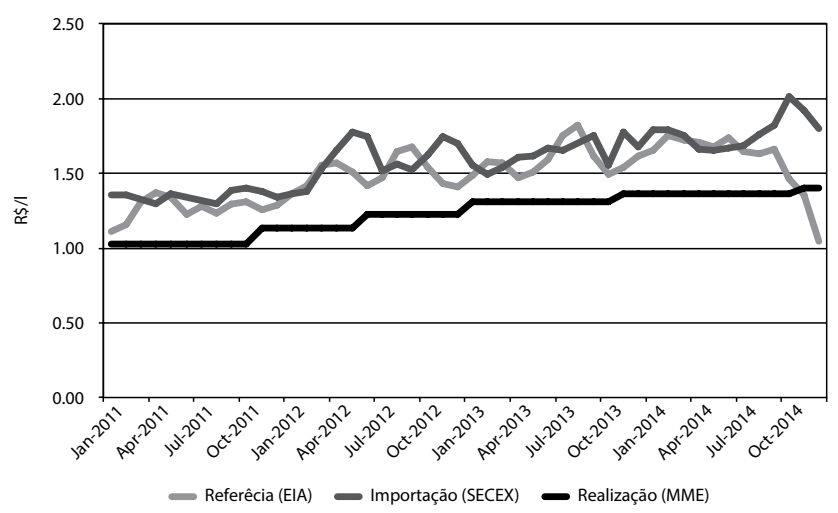

Fonte: Elaboração própria a partir de dados da ANP e EIA-DOE.

tica foram reajustados e ficaram acima dos preços de referência, mas abaixo dos preços de importação.

Já o GLP apresentou uma diferença maior entre o preço pago com as importações e os preços de referência internacional. No entanto, ambos têm, em certa medida, a mesma tendência (Gráfico 6). Os preços de importações foram superiores aos preços vendidos internamente tanto no caso do GLP industrial, quanto no caso do residencial. Quanto aos preços de referência, eles são em sua maior parte superiores aos preços de realização residencial e somente ficam superiores ao preço de realização industrial a partir de novembro de 2013. Com a queda do preço do propano no mercado norte-americano, os preços domésticos do GLP residencial ficaram no mesmo patamar do preços de referência, mas abaixo do preço de importação do GLP.

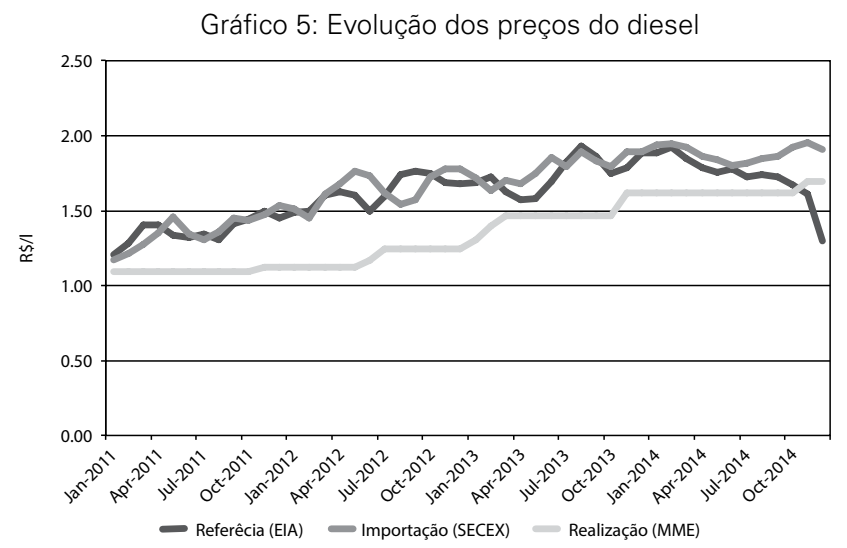

Fonte: Elaboração própria a partir de dados da ANP e EIA-DOE. 
Gráfico 6: Evolução dos preços do GLP

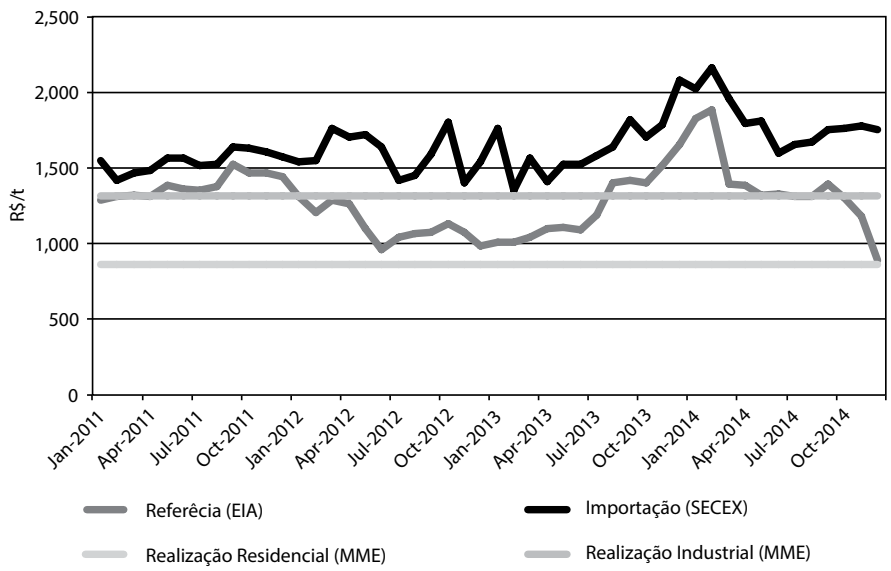

Fonte: Elaboração própria a partir de dados da ANP e EIA-DOE.

\section{IMPACTOS ECONÔMICOS DA POLÍTICA DE CONTROLE DE PREÇOS}

\section{Impactos sobre a Petrobras}

O Gráfico 7 apresenta as perdas financeiras da Petrobras decorrentes do combustível importado a preços distintos aos de realização interna. As maiores perdas com importações no setor de abastecimento desses três derivados ocorreram para o diesel em 2012, ano em que houve a maior perda para a empresa. Depois do diesel, as importações de gasolina proporcionaram as maiores perdas para a empresa em 2012, enquanto em 2011, 2013 e 2014 o GLP foi o segundo maior responsável.

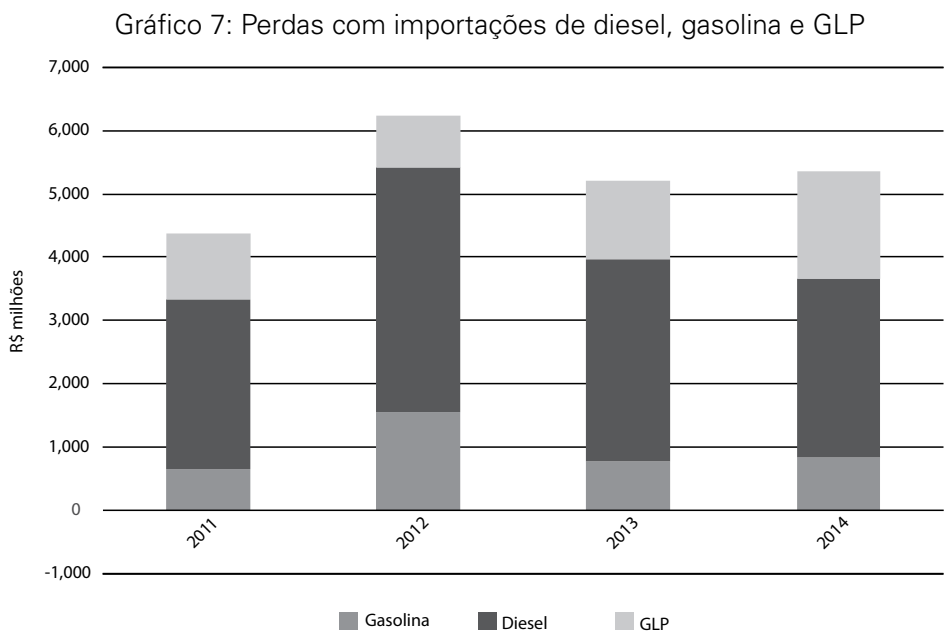

Fonte: Elaboração própria. 
A Tabela 1 mostra que as perdas com as importações dos três derivados somaram R \$ 21 bilhões de reais até 2014.

Tabela 1: Perdas com combustível importado 2011-2014 (R \$ milhões)

\begin{tabular}{lllll}
\hline & Gasolina & Diesel & GLP & Total \\
\hline Somatório & 3.808 & 12.569 & 4.897 & 21.273 \\
\hline
\end{tabular}

Fonte: Elaboração própria.

O Gráfico 8 apresenta as perdas de receitas da Petrobras por não praticar o preço internacional na venda de combustíveis. O diesel foi o combustível que proporcionou as maiores perdas de receitas à Petrobras no período, seguido da gasolina.

Gráfico 8: Perdas de receita nas vendas de diesel, gasolina e GLP

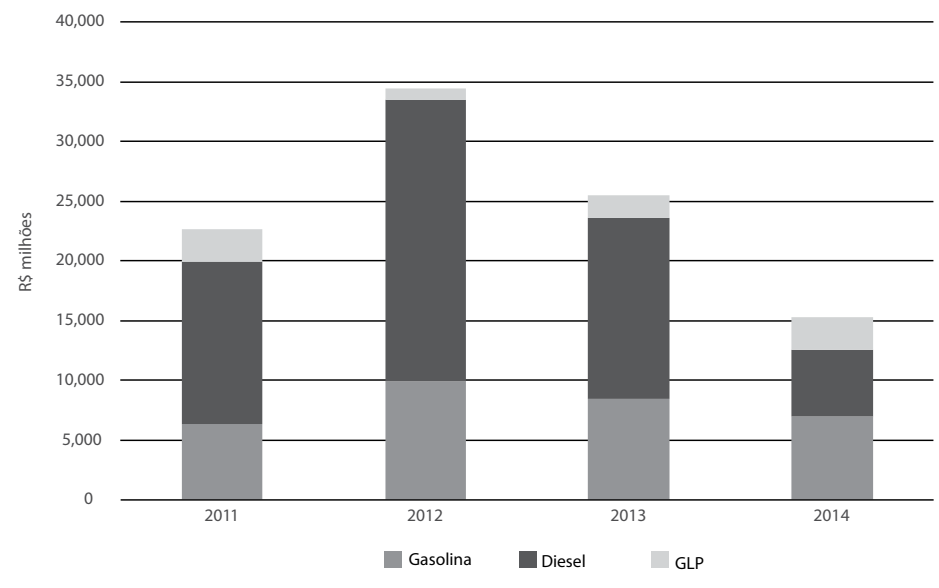

Fonte: Elaboração própria.

Segundo a Tabela 2, as perdas de receita decorrentes da venda de derivados a um preço inferior ao de referência internacional totalizaram $\mathrm{R} \$ 98$ bilhões entre 2011 e 2014.

\begin{tabular}{ccccc}
\multicolumn{4}{c}{ Tabela 2: Perdas nas receitas de combustivel } & 2011-2014 (R\$ milhões) \\
\hline & Gasolina & Diesel & GLP & Total \\
\hline Somatório & 31.751 & 57.687 & 8.460 & 97.897 \\
\hline
\end{tabular}

Fonte: Elaboração própria.

Os impactos negativos do desalinhamento dos preços na Petrobras são claros quando se observa alguns indicadores financeiros da empresa. Como mostra o Gráfico 9, a dívida da Petrobras aumentou em mais de 70\% de 2011 a 2013, sendo o aumento mais forte de 2012 para 2013 (36\%). Barbosa (2013) mostra que o crescimento da dívida líquida foi ainda maior (mais que dobrou). Em termos absolutos, entre 2011 e 2013 a dívida bruta e a líquida cresceram mais de R \$ 100 bilhões. 
Gráfico 9: Dívida total e dívida líquida da Petrobras (2011-2013)

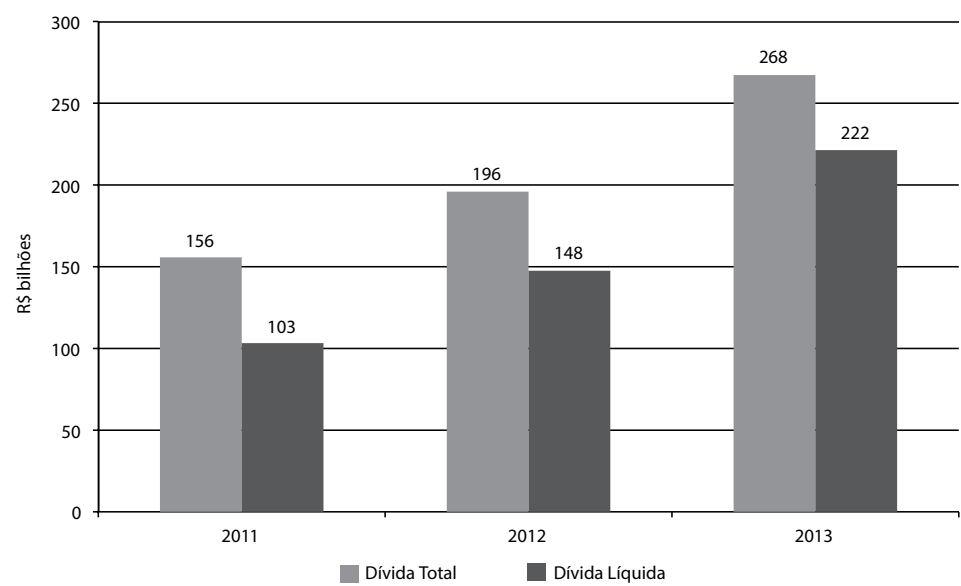

Fonte: Barbosa (2014)

O Gráfico 10 apresenta o indicador dívida líquida/EBITDA ajustado. Segundo os dados apresentados por Barbosa (2013), esse indicador mais que dobrou de 2011 a 2013 no caso da Petrobras. Esse movimento ocorreu em função de uma geração de caixa insuficiente para arcar com o elevado ritmo dos investimentos. Em parte, o baixo crescimento da geração de caixa está associado ao desalinhamento dos preços.

Gráfico 10: Indicador dívida líquida sobre EBITDA ajustado (2011-2013)

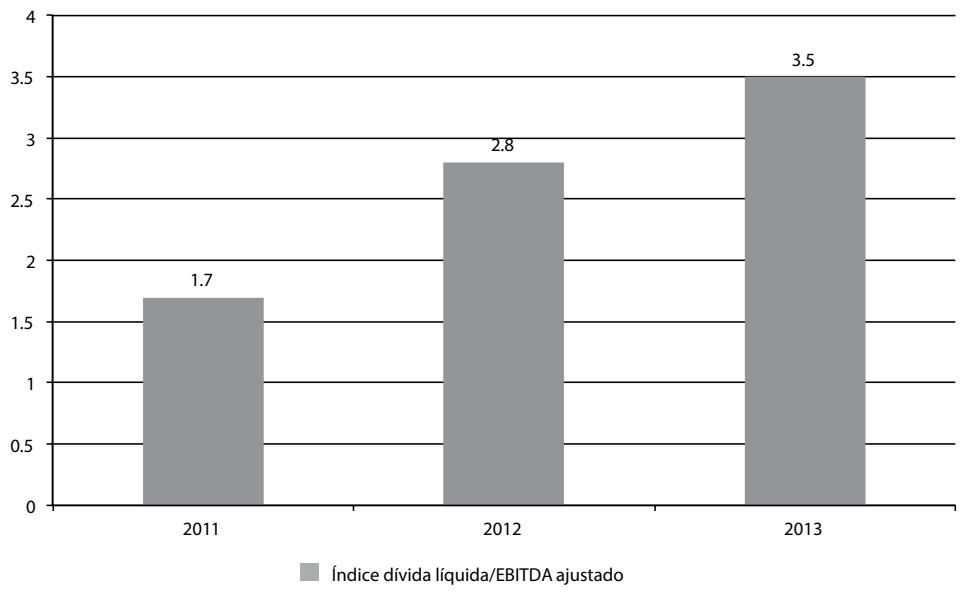

Fonte: Barbosa (2014). 
Considerando-se o resultado líquido por segmento de negócios da empresa fica claro que parte significativa da deterioração financeira da empresa se deve aos resultados do segmento de abastecimento. Analisando-se o pior ano de desempenho da empresa no período pode-se perceber que em 2012 o lucro total da Petrobras foi inferior ao próprio prejuízo do segmento de abastecimento (Tabela 4).

Tabela 3: Resultado líquido por segmento de negócio da Petrobras 2010-2014 (2T) (R \$ milhões)

\begin{tabular}{lccccc}
\hline Segmento & 2010 & 2011 & 2012 & 2013 & $2014(2 \mathrm{~T})$ \\
\hline E\&P & 29.558 & 40.575 & 45.452 & 42.266 & 21.447 \\
\hline Abastecimento & 3.796 & -9.970 & -22.931 & -17.764 & -8.691 \\
\hline Gás e energia & 1.247 & 3.138 & 1.733 & 1.387 & 1.217 \\
\hline Biocombustível & -92 & -157 & -218 & -254 & -141 \\
\hline Distribuição & 1.276 & 1.175 & 1.793 & 1.843 & 956 \\
\hline Internacional & 1.398 & 1.967 & 1.436 & 3.775 & 1.143 \\
\hline Total & 35.881 & 33.110 & 20.959 & 23.007 & 10.977 \\
\hline
\end{tabular}

Fonte: Petrobras.

Adicionalmente, o valor de mercado da empresa foi reduzido a partir de 2010, revertendo a tendência de alta do ano anterior. Como mostra a Gráfico 11, entre 2010 e 2013 o valor de mercado da empresa se reduziu em $43 \%$.

Gráfico 11: Valor de mercado da Petrobras 2009 a 2013

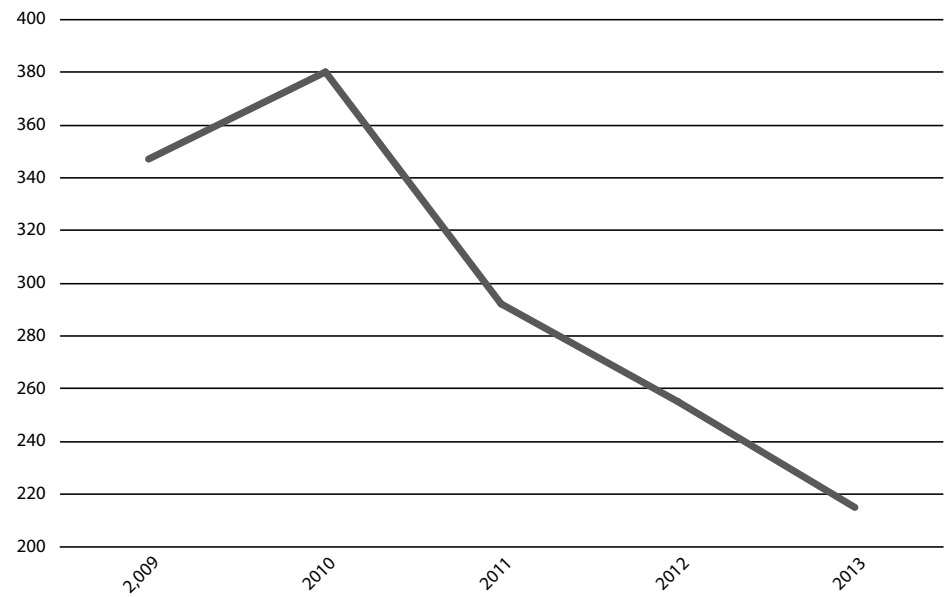

Fonte: Petrobras (2014) 


\section{Impactos na dinâmica de investimentos da indústria brasileira de petróleo}

A organização da indústria de petróleo brasileira foi impactada pela atual política de preços de derivados, principalmente no que concerne ao segmento de refino. Como apontam Colomer e Tavares (2012), sendo a Petrobras responsável por quase a totalidade da capacidade de refino do país, a política de preços adotada pela empresa determina os preços domésticos dos combustíveis e, consequentemente, a margem de rentabilidade do refino. No contexto de desalinhamento dos preços domésticos, a margem de refino no Brasil tem se distanciado da lucratividade internacional média do segmento. Consequentemente, o segmento de refino nacional não apresenta atratividade para outras empresas que não a Petrobras (Accioli e Monteiro, 2013).

Os investimentos significativos em refino foram feitos nos anos 1980, quando o parque brasileiro foi consolidado. Durante um longo prazo, a capacidade de refino se manteve estagnada, sem a construção de novas refinarias. Nesse intervalo, a expansão correspondeu apenas à ampliação de unidades existentes (Revamps). A capacidade de refino nacional cresceu a uma taxa de apenas $0,7 \%$ a.a. entre 2002 e 2012 (Tabela 4). Para reverter esse quadro, a Petrobras iniciou um grande esforço para aumentar a capacidade de refino nacional, através dos seguintes projetos: Abreu Lima (Pernambuco), Comperj (Rio de Janeiro), Premium I (Maranhão) e Premium II (Ceará). Entretanto, como os investimentos não são atrativos para outras empresas, autossuficiência no suprimento de derivados não deve ser atingida antes de 2020 .

Apesar de menos concentradas que o refino, as atividades de distribuição de combustíveis e revenda estiveram marcadas pela forte presença da estatal em 2013. Nesse ano, a Petrobras foi, por meio da Distribuidora BR, responsável por 36,6\% da distribuição de óleo diesel e 28,5\% no caso da gasolina. A Liquigás, subsidiária da estatal responsável pela distribuição de GLP, deteve o segundo lugar $(22,6 \%)$ na participação do segmento em 2013 (Quadro 2).

A bandeira da estatal respondeu por $20 \%$ dos postos revendedores em 2013, sendo líder do mercado. O conjunto de postos revendedores de bandeira branca, que não exibem marca comercial de nenhuma distribuidora, tem participação de $40,7 \%$ no segmento de revenda.

Dessa forma, após mais de uma década da liberalização do mercado brasileiro, o abastecimento doméstico depende quase totalmente da Petrobras, por sua predominância no refino. Assim, o peso da empresa tanto no refino quanto nas atividades de distribuição e revenda tem implicações significativas para a concorrência da indústria.

A concorrência no mercado de combustíveis no Brasil poderia ocorrer através da importação de derivados e da produção interna nas refinarias. Além das dificuldades óbvias de enfrentar uma empresa dominante como a Petrobras, na situação de preços domésticos inferiores ao do mercado internacional, a importação é inviável. 


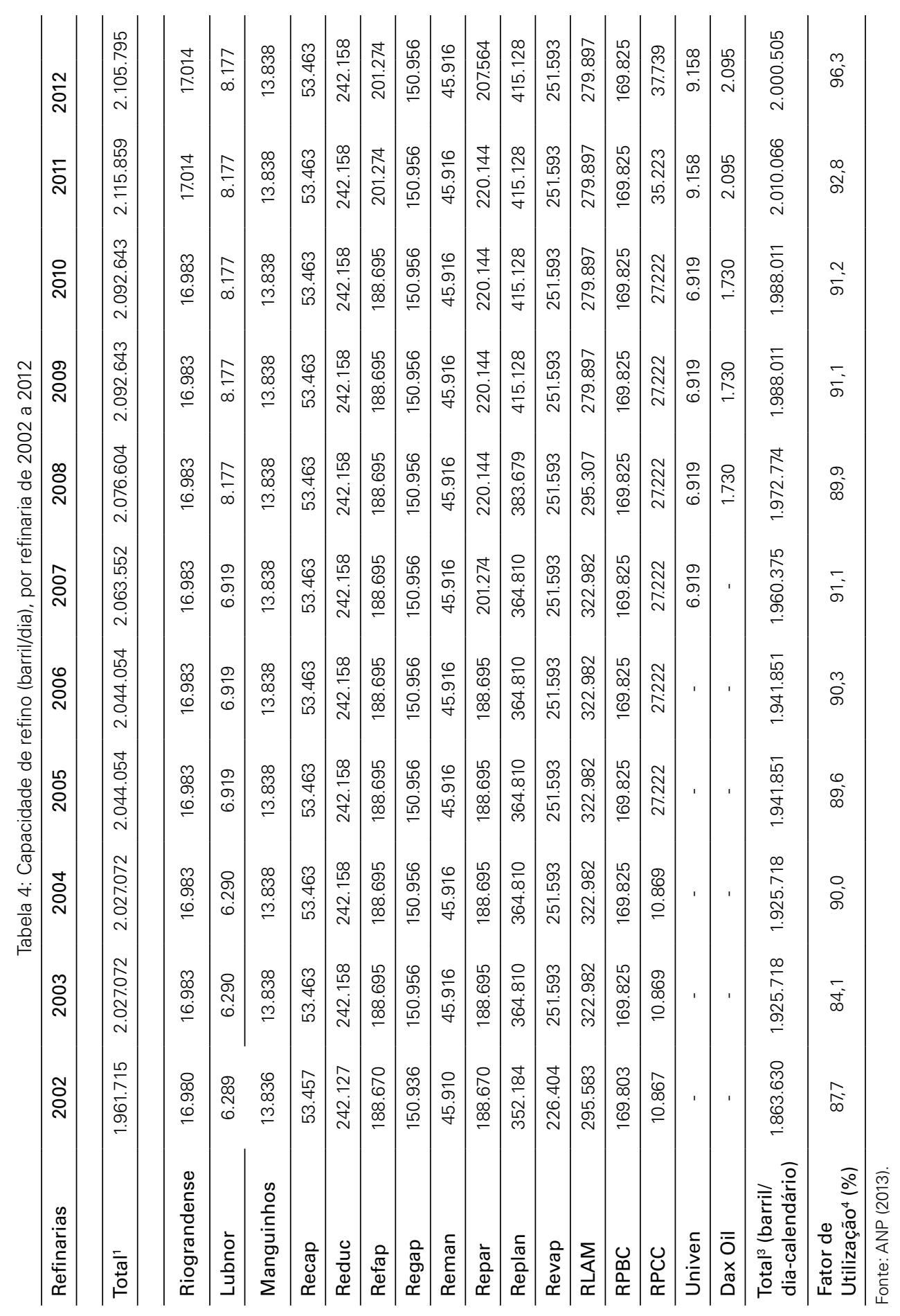


Quadro 2: Evolução da participação das principais distribuidoras nas vendas nacionais de diesel, gasolina C e GLP

\begin{tabular}{|c|c|c|c|c|c|}
\hline Derivado & Distribuidora & 2010 & 2011 & 2012 & 2013 \\
\hline \multirow{6}{*}{ Gasolina C } & $\mathrm{BR}$ & $30 \%$ & $30 \%$ & $29 \%$ & $29 \%$ \\
\hline & Ipiranga & $20 \%$ & $20 \%$ & $20 \%$ & $21 \%$ \\
\hline & Shell* & $11 \%$ & \multirow{2}{*}{$17 \%$} & \multirow{2}{*}{$16 \%$} & \multirow{2}{*}{$16 \%$} \\
\hline & Cosan* & $7 \%$ & & & \\
\hline & Alesat & $6 \%$ & $5 \%$ & $5 \%$ & $6 \%$ \\
\hline & Total & $2 \%$ & $2 \%$ & $2 \%$ & $2 \%$ \\
\hline \multirow{6}{*}{ Óleo diesel } & $\mathrm{BR}$ & $41 \%$ & $40 \%$ & $39 \%$ & $37 \%$ \\
\hline & Ipiranga & $22 \%$ & $23 \%$ & $23 \%$ & $23 \%$ \\
\hline & Shell* & $10 \%$ & \multirow{2}{*}{$15 \%$} & \multirow{2}{*}{$14 \%$} & \multirow{2}{*}{$15 \%$} \\
\hline & Cosan* & $6 \%$ & & & \\
\hline & Alesat & $3 \%$ & $3 \%$ & $3 \%$ & $3 \%$ \\
\hline & Sabba & $2 \%$ & $2 \%$ & $2 \%$ & $2 \%$ \\
\hline \multirow{6}{*}{ GLP } & Ultragaz & $23 \%$ & $23 \%$ & $23 \%$ & $23 \%$ \\
\hline & Liquigás & $22 \%$ & $23 \%$ & $23 \%$ & $23 \%$ \\
\hline & SHV Gas Brasil & $22 \%$ & $21 \%$ & $21 \%$ & $21 \%$ \\
\hline & Nacional Gás & $19 \%$ & $19 \%$ & $19 \%$ & $19 \%$ \\
\hline & Copagaz & $7 \%$ & $8 \%$ & $8 \%$ & $8 \%$ \\
\hline & Consigaz & $2 \%$ & $2 \%$ & $3 \%$ & $3 \%$ \\
\hline
\end{tabular}

* Cosan e Shell criaram a Raízen em 2011

Fonte: Elaboração própria a partir de dados de ANP (2014b).

Quadro 3: Evolução da participação das principais bandeiras na revenda de combustíveis automotivos

\begin{tabular}{|c|c|c|c|c|}
\hline Bandeira & 2010 & 2011 & 2012 & 2013 \\
\hline Branca & $43,6 \%$ & $43,3 \%$ & $42,3 \%$ & $40,7 \%$ \\
\hline $\mathrm{BR}$ & $19,9 \%$ & $19,9 \%$ & $19,9 \%$ & $20,0 \%$ \\
\hline Ipiranga & $13,4 \%$ & $13,8 \%$ & $14,2 \%$ & $14,8 \%$ \\
\hline Shell* & $5,8 \%$ & \multirow{2}{*}{$9,5 \%$} & $9,8 \%$ & \multirow{2}{*}{$10,0 \%$} \\
\hline Cosan* & $4,0 \%$ & & & \\
\hline Alesat & $3,6 \%$ & $3,6 \%$ & $3,7 \%$ & $3,8 \%$ \\
\hline
\end{tabular}

*Cosan e Shell criaram a Raízen em 2011

Fonte: Elaboração própria a partir de dados de ANP (2014b).

A construção de refinarias ou a participação de outras empresas em refinarias da Petrobras representam uma segunda opção de entrada no mercado de combustíveis brasileiro. Neste caso, a política de preços dos combustíveis representa o principal risco para novos entrantes. A política atual pautada pelo controle da 
inflação, associada à posição dominante da Petrobras no refino, tem implicado condições pouco atrativas para o investimento privado (e da própria estatal) em refino, para o qual o preço definido é o que importa do ponto de vista da determinação dos preços.

Desta forma, se a atual política de precificação de derivados se mantiver no Brasil, é pouco provável que ocorra um processo de desconcentração do mercado de refino de petróleo e importações de derivados no Brasil. Tendo em vista a perspectiva de elevação da produção de petróleo no Brasil num contexto de abertura do upstream nacional, o país caminha para uma configuração futura na qual empresas estrangeiras produzem e exportam petróleo no Brasil e o monetizam em condições mais vantajosas que a Petrobras, quando os preços domésticos estão defasados.

Podemos concluir que a modificação da política de preços atual é imprescindível para uma expansão equilibrada do segmento do refino nacional.

\section{OPÇÕES DE PRECIFICAÇÃO}

Existem diversas opções de políticas em relação à precificação de derivados. Além dos mercados totalmente liberalizados, que podem ser compreendidos especialmente a partir de estudos de casos de países como o Canadá e os Estados Unidos, podem ser considerados os resultados, apontados pela literatura internacional, de políticas de vários países que buscaram controlar os preços dos derivados de petróleo.

O simples alinhamento no curto prazo dos preços domésticos aos internacionais enfrenta barreiras políticas no Brasil, uma vez que tornariam os preços domésticos vulneráveis à volatilidade do mercado internacional ${ }^{3}$. Ainda que pareça ser uma opção politicamente difícil para o país, a possibilidade de total liberalização é discutida nesta seção. Em seguida, serão apresentadas as experiências internacionais relativas às medidas de controle de preços. Estas, em geral, compreendem o estabelecimento de fundos de estabilização que, combinados a regras de precificação, têm o intuito de amortecer o repasse da volatilidade dos preços internacionais aos preços domésticos. Porém, como será visto, essas iniciativas podem acabar se tornando um mecanismo de subsídio.

É evidente, então, a necessidade de se considerar um mecanismo de amortecimento dos preços diferente para o Brasil: uma política que evite o subsídio mas, ao mesmo tempo, permita a previsibilidade das mudanças de preços e, consequentemente, a redução dos riscos de investimento de potenciais entrantes no mercado doméstico de combustíveis.

\footnotetext{
${ }^{3}$ Cabe ressaltar que a volatilidade dos preços do petróleo no mercado internacional manteve-se num patamar muito baixo a partir de 2010. Neste sentido, a questão da volatilidade dos preços internacionais não foi um problema relevante para a política de preços domésticos nos últimos anos.
} 


\section{Mercados competitivos de combustíveis}

Atualmente existem vários mercados de combustíveis liberalizados. Além dos mercados canadense e americano, existem países em desenvolvimento com mercados de combustíveis liberalizados. Neste caso, é perceptível a instabilidade quanto à definição desse tipo de política, especialmente após meados de 2009, quando os preços do petróleo mostraram uma elevação permanente, inúmeros países em desenvolvimento reduziram o ritmo do processo de liberalização dos preços que vinham implementando, ou até mesmo reverteram essa tendência, estabelecendo algum tipo de controle (Kojima, 2013).

\section{Países em desenvolvimento}

Dentre os 65 países em desenvolvimento analisados por Kojima (2013) pode-se destacar os seguintes que não possuíam controle de preços recentemente: Camboja, Guatemala, Turquia e Uganda. O Quadro 4 a seguir apresenta o coeficiente de repasse ${ }^{4}$ dos preços no varejo desses países, incluindo também o Brasil, a título de comparação.

\begin{tabular}{|c|c|c|c|}
\hline País & Gasolina & Diesel & GLP \\
\hline Camboja & 133 & 142 & 155 \\
\hline Guatemala & 101 & 100 & 11 \\
\hline Turquia & 127 & 175 & 165 \\
\hline Uganda & 12 & 14 & 209 \\
\hline Brasil & 57 & 30 & 199 \\
\hline
\end{tabular}

Fonte: Kojima, 2013.

Camboja e Turquia tiveram os coeficientes mais elevados. No caso da Turquia existe uma grande assimetria no repasse, impulsionada principalmente pela tributação que se eleva quando os preços internacionais se elevam, mas diminuem em proporção inferior quando os preços se reduzem. Adicionalmente, a Turquia se sobressai por apresentar os preços mais elevados para a gasolina e o diesel, e um dos mais altos para o GLP, o que se deve, em parte, à tributação elevada (49\% do preço da gasolina, 39\% do diesel e 32\% do GLP residencial) (IEA, 2012).

No caso da Guatemala, o governo publica o preço semanal da gasolina e diesel em diferentes partes do país e o preço médio do GLP por tamanho do cilindro e tamanho da empresa. Já Uganda, que apresentou um dos maiores preços do GLP, obteve um coeficiente relativamente baixo, apesar da ausência de controle nos preços, devido a fatores externos como crises de oferta, principalmente por restri-

${ }^{4} \mathrm{O}$ coeficiente de repasse é calculado como Kojima, 2012. 
ções no Quênia (passagem para a oferta de combustíveis na Uganda através de estrada e oleodutos e ferrovias), que elevaram substancialmente os preços em 2009 (ano-base para o cálculo do coeficiente).

Como era de esperar, a comparação desses países com o Brasil mostra um coeficiente de repasse doméstico deste relativamente baixo.

Os países que possuem mercados de combustíveis historicamente competitivos são os norte-americanos do Canadá e dos Estados Unidos, sendo, portanto, casos relevantes para se estudar efeitos de políticas de liberalização de preços.

\section{Canadá}

No caso do Canadá, os preços dos derivados de petróleo, que permaneceram regulados entre 1974 a 1985, foram liberalizados a partir do "Western Accord" 5 em 1985. A remoção dos controles visava à garantia do fornecimento de derivados de petróleo a preços competitivos e o fornecimento de informação mais acurada sobre o valor do combustível tanto para os produtores e suas decisões de investimento, quanto para os consumidores, para que ajustem o próprio consumo (Canadá, 2014).

Adicionalmente, o acordo do Tratado Norte-Americano de Livre Comércio (NAFTA) exige que os produtores canadenses ofereçam seu petróleo cru aos parceiros comerciais sob as mesmas condições oferecidas às refinarias canadenses. Logo, a liberalização permite que os produtores de petróleo canadenses não sejam obrigados a aceitar preços inferiores de vendas a refinarias domésticas ou em termos do NAFTA, sendo livres para vender no mercado mundial aos preços internacionais (Canadá, 2014).

À exceção de uma emergência nacional, o governo do Canadá não tem jurisdição sobre a regulação direta dos preços dos combustíveis, apenas as províncias ${ }^{6}$. Segundo o governo do Canadá (2014), apesar de os preços serem regulados em algumas províncias, essas iniciativas não resultaram em preços menores aos consumidores, mas tiveram resultados em termos de obtenção de preços mais estáveis, sendo este o objetivo principal desse tipo de política no país.

Existem dois tipos de tributos que recaem sobre os derivados de petróleo no Canadá. O primeiro deles, é um imposto fixo no qual o governo federal cobra um imposto sobre o consumo de 10 centavos por litro na gasolina (desde 1995) e 4 centavos por litro no diesel (desde 1987), sendo o propano isento desse imposto. Há também impostos de províncias, que podem variar consideravelmente, e de alguns municípios do país. O segundo tipo, é um imposto sobre as vendas que corresponde a uma taxa de $5 \%$ sobre bens e serviços (exceto em algumas províncias, que o substituem). Ou seja, é um imposto ad valorem que pode variar dependendo do preço do combustível.

\footnotetext{
${ }^{5}$ Acordo entre as quatro províncias que compunham o Canadá à época: Canadá, Alberta, Saskatchewan e British Columbia.

${ }^{6}$ As províncias Prince Edward Island, Newdoundland and Labrador, Nova Scotia, New Brunswick e Quebec regulam os preços de alguma maneira.
} 
Os preços dos combustíveis no Canadá são explicados majoritariamente pelo preço mundial do petróleo, além dos custos de transporte, margens de refino e marketing, níveis de estoque e condições de oferta local e as sazonalidades, sendo que os tributos também compõem seus preços.

\section{Estados Unidos}

O mercado de combustíveis também é totalmente liberalizado nos Estados Unidos e a composição dos preços e os seus determinantes são semelhantes ao do mercado canadense, sendo influenciados principalmente pela interação entre oferta e demanda.

Segundo a EIA (2014), os preços da gasolina e do diesel nos postos dependem do preço do petróleo, dos custos e margem de refino e das margens de distribuição, comercialização, além dos impostos, como mostra o Gráfico 12.

\section{Gráfico 12: Composição do preço do galão de diesel e de gasolina}

Diesel

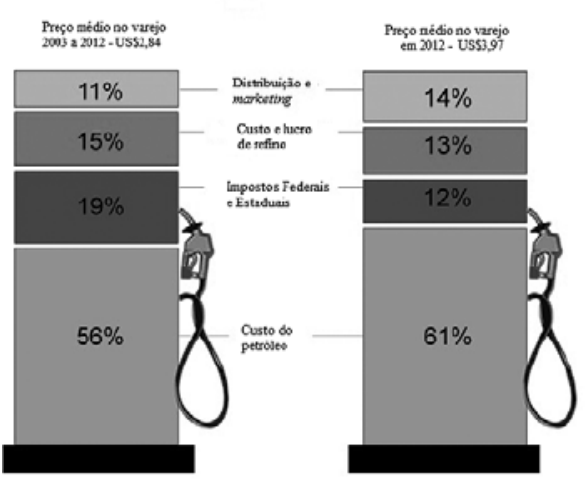

Gasolina

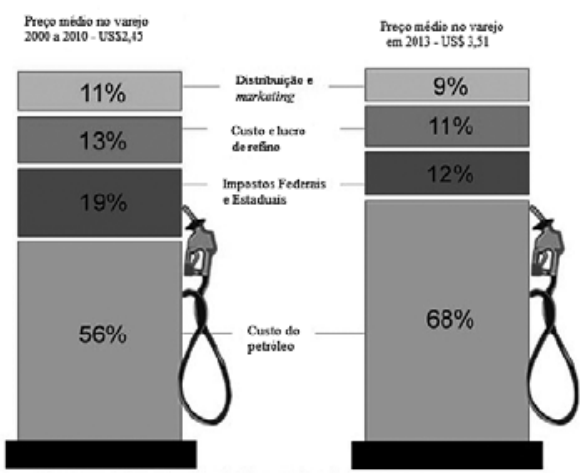

Fonte: Elaboração própria, baseada em EIA (2014)

Em 2012, os impostos fixos federais ${ }^{7}$ foram de US\$ 18,4 centavos por galão de gasolina. No caso do diesel, os impostos eram de US\$ 24,8 centavos por galão (EIA, 2014). Diferentemente do Brasil, nos Estados Unidos existem postos de revenda que são de propriedade e operados pelas refinarias, bem como iniciativas independentes que compram gasolina ou diesel para revenda ao público. Historicamente, o preço médio do diesel foi inferior ao da gasolina ${ }^{8}$. Entretanto, desde 2004 o preço do diesel tem se mantido mais elevado que o da gasolina. Apesar de outras influências ${ }^{9}$, isso se deve ao fato de a demanda mundial (puxada pela China,

\footnotetext{
${ }^{7}$ Além dos impostos federais, a taxa média de imposto estadual foi de US\$24,16 centavos por galão de gasolina em 2013. Alguns estados, condados ou cidades também incluem outros impostos.

${ }^{8}$ Com exceção dos períodos de inverno, quando a demanda por óleo combustível se eleva, elevando os preços do diesel a patamar superior ao da gasolina.

${ }^{9}$ Outras influências dizem respeito à transição, nos Estados Unidos, para o diesel de baixo teor de
} 
Europa e Estados Unidos) por diesel e outros óleos de aquecimento terem crescido a taxas maiores que a de gasolina, sendo que as refinarias não foram capazes de responder com produção.

Os preços da gasolina e do diesel nos postos também podem variar de acordo com as condições locais de mercado, que estão relacionadas às estratégias do proprietário do posto, sua localização e número de competidores. As variações sazonais na demanda ${ }^{10}$ são também outro fator a afetar os preços dos derivados, mesmo quando os preços de petróleo estão estáveis.

Já o preço do propano está mais sujeito a sazonalidades que o diesel e a gasolina. Ele sofre todas as influências comuns aos derivados de petróleo além de estar sujeito a outros fatores como os preços de combustíveis substitutos, a distância até o consumidor e o volume utilizado por ele. Por servir diferentes mercados, o propano sofre a competição direta de cada combustível substituto em cada um desses mercados: residencial, petroquímico e de produção agrícola. Adicionalmente, seu preço varia segundo a distância em relação ao consumidor e volume vendido, devido às economias de escala que reduzem seu custo unitário.

O Gráfico 13 mostra como os preços da gasolina, diesel e propano no varejo evoluíram nas últimas décadas em relação ao preço do petróleo.

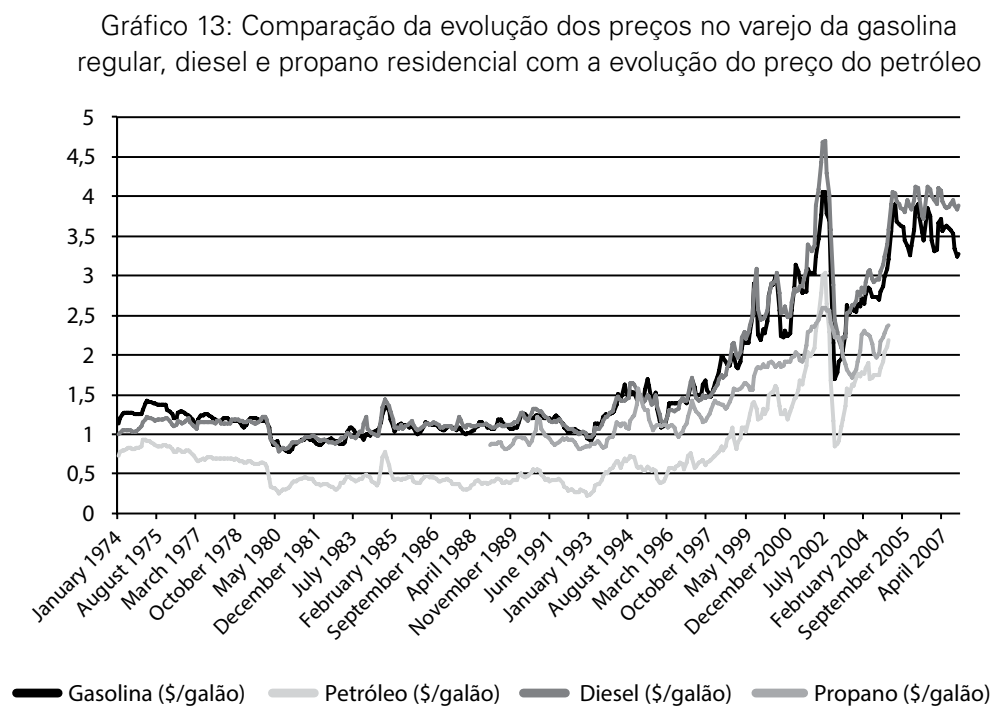

Fonte: EIA (2014).

enxofre, o que afetou os preços de produção e distribuição, e ao tributo mais elevado do diesel em relação à gasolina.

${ }^{10}$ Os preços da gasolina tendem a se elevar na primavera e atingem um pico no verão. No caso do diesel eles se elevam no outono e no inverno, principalmente pelo aumento da demanda de óleo combustível, por serem substitutos próximos. O preço do GLP se eleva no inverno, principalmente devido à calefação. 
A evolução dos preços desses derivados mostra a tendência de alta e a volatilidade a qual estão sujeitos, pois respondem às variações de oferta e demanda mundial. Em países desenvolvidos e com taxa de inflação baixa e estável como o Canadá e os Estados Unidos, parece ser mais factível manter esse tipo de mercado. O mesmo pode não ser verdade para países em desenvolvimento e que tendem a ter maior preocupação com os impactos que as variações de demanda e oferta internacional podem ter nos preços domésticos e, respectivamente, na inflação. É nesse sentido que muitos desses países acabam optando por política de controle dos preços dos derivados.

\section{Fundos de estabilização versus subsídios}

Os fundos de estabilização de preços geralmente vêm acompanhados de uma regra de precificação (faixa de preços, média móvel, etc.). Segundo Frederico et al. (2001), em 2001 aproximadamente cerca de um quarto dos países que regulavam preços possuíam fundos de estabilização específicos para gerir o processo de suavização, sendo que alguns os eliminaram, principalmente devido a seu elevado custo fiscal.

A utilidade de um fundo de estabilização dependerá do tipo do choque dos preços internacionais (permanente ou temporário). Quanto mais persistente o choque, maiores serão os custos de se manter um preço doméstico artificial. Além dos tipos de choque, existem outros aspectos a serem considerados no desenvolvimento de uma política de estabilização de preços, pois, ainda que o choque seja temporário, a habilidade de estabilizar os preços dependerá da persistência e duração dos ciclos. Em outras palavras, mesmo que os choques não sejam permanentes, se a variância dos preços for pequena, e haja grandes choques raros, os ganhos serão relativamente menores. Os benefícios que podem ser obtidos dos fundos de estabilização serão maiores em ambientes mais voláteis e incertos (Reinhart e Wickham, 1994).

Os fundos de estabilização permitem que o petróleo ou seus derivados flutuem dentro de uma faixa previamente especificada. Quanto menor a banda, maior o uso de acumulação de recursos no fundo. Quer dizer, qualquer volatilidade de preços não coberta pela banda é transferida para o fundo. Se os preços exibirem uma tendência sustentada e os limites inferiores e superiores da banda não forem ajustados em tempo hábil, os recursos do fundo tendem a se esgotar (no caso da tendência ascendente) ou a crescer indefinidamente (decrescente) (Zapata, 2012).

Em teoria, os fundos de estabilização de preços deveriam ser autofinanciados ao longo do tempo. No entanto, na prática, a maioria dos fundos de estabilização de países em desenvolvimento estudados por Kojima (2013) acabaram recebendo transferências orçamentárias, ou, como no caso da Tailândia, tiveram que tomar empréstimos. Isso significa que, para lidar com o problema da volatilidade, a alternativa de estabelecer fundos de estabilização, pode acabar se tornando uma fonte de subsídio.

As definições sobre o que pode ser considerado subsídio são as mais diversas. 
O acordo sobre subsídios e medidas compensatórias da Organização Mundial de Comércio (OMC, 1994), que envolve 153 países, define que o subsídio existe quando há uma vantagem proveniente de qualquer forma de receita ou sustentação de preços no sentido do Artigo XVI do GATT (1994) ou quando há uma contribuição financeira do governo ou de qualquer ente público que envolva: i) a transferência direta de fundos, potenciais transferências de fundos ou obrigações (garantias de empréstimos, por ex.); ii) a renúncia ou não coleta uma receita do governo; iii) o fornecimento de bens ou serviços além da infraestrutura geral ou quando adquire bens; iv) pagamentos para um mecanismo de fundo ou instrução para um ente privado fazer as funções definidas nos itens anteriores, que normalmente seriam de incumbência do governo e cuja prática não se diferencie de modo significativo daquela seguida pelo governo.

Ao analisar os subsídios no setor de energia, o FMI (2013) ressalta a dificuldade de distinguir na prática os subsídios ao consumidor de subsídios ao produtor, e atenta para o fato de que, diferentemente do primeiro, o subsídio ao produtor não leva a um consumo excessivo.

O subsídio ao consumidor possui dois componentes: o pré-imposto e o pós-imposto. O subsídio pré-imposto (Subsídio pré-imposto $=\mathrm{Pw}-\mathrm{Pc}$ ) ocorre quando o preço pago está abaixo do custo de oferta e de distribuição, enquanto o subsídio pós-imposto (Subsídio pós-imposto $=(\mathrm{Pw}+\mathrm{t})-\mathrm{Pc}$ ) existe quando os impostos estão abaixo de seu nível eficiente t. Imposto eficiente é aquele no qual todo o consumo, incluindo de produtos energéticos, está sujeito ao imposto - no caso de energia requereria também imposto adicional para capturar impactos negativos de suas externalidades. Pc é preço pago pelo consumidor e Pw é o preço de benchmark, que é o preço internacional ajustado aos custos de transporte e distribuição (FMI, 2013).

Segundo o Instituto Internacional para o Desenvolvimento Sustentável (International Institute for Sustainable Development - IISD, 2010), o relatório do G-20 afirmava que não existiriam subsídios ineficientes aos combustíveis no Brasil. Mesmo recentemente, se olharmos pela ótica do FMI (2013) explicitada acima, a redução da CIDE e posterior zeragem de sua alíquota desde 2012 no Brasil não conferiria um subsídio, já que este imposto seria referente apenas aos combustíveis e não incidiria sobre todos os bens de consumo.

\section{Fundo de estabilização do Chile}

Os estudos de caso a seguir são apresentados de acordo com Valero (2010).

Após haver implementado o Fundo de Estabilização de Preços de Petróleo (FEPP) em 1991, modificado em 2000, o Chile substituiu temporariamente (desde 2005) o fundo pelo Fundo de Estabilização de Preços de Combustíveis.

O FEPP, que incluía gasolina, diesel, GLP, nafta, querosene doméstico e óleo combustível, foi constituído por um fundo de US\$ 200 milhões emprestados do Fundo de Estabilização do Cobre. As retiradas e contribuições seriam feitas mediante uma banda de preços (amplitude de $+/-12,5 \%$ em relação ao preço de referência intermediário-PRIn fixado pelo ministério) fixada pelo Ministério de Mine- 
ração. Caso o preço rompesse a banda, era criado um imposto $(60 \%$ da diferença entre o piso e a banda e o preço internacional) transferido ao FEPP e, quando o preço rompesse o teto o fundo cobriria $100 \%$ da diferença, subsidiando-os.

Desde sua implementação até o ano 2000, foi verificado que o FEPP operou corretamente quando as condições de mercado permitiram, pois em períodos de preços elevados (1999-2000) o aumento dos preços não foi transmitido aos consumidores e o FEPP não operou, acarretando ônus à Empresa Nacional de Petróleo (ENAP). Adicionalmente, a banda foi afetada pelo sistema de ajuste do PRIn, que pode ter tido a interferência do governo. Por último, os recursos acumulados no fundo não foram suficientes para garantir a estabilização dos preços, levando o Estado a contribuir adicionalmente com US\$ 200 e US\$ 50 milhões em fevereiro e julho de 2000.

De fato, como ressaltou Valero (2010), não havia sido estabelecido um mecanismo claro de ajuste para o nível central das bandas de preços, que ficou sujeito à discricionariedade do governo, e o fundo, por sua natureza, ficou exposto ao esgotamento de seus recursos em cenários de altos preços de petróleo. Assim, o Chile modificou a operação do FEPP (maior transparência e novas fórmulas para evitar o esgotamento do fundo, além de corrigir a disparidade para as contribuições e retiradas), para estabelecer o novo FEPP de 2000.

As novas fórmulas estabelecidas para fixar as contribuições e retiradas do fundo não tiveram sucesso, já que, ao se esgotar progressivamente, transmitiam em maior proporção a volatilidade dos preços aos consumidores e, no fim, não evitaram o esgotamento (devido ao crescimento sustentado dos preços) e posterior transformação do fundo em 2005. Criou-se então um novo Fundo de Estabilização de Preços dos Combustíveis (FEPC) que seria financiado pelos rendimentos financeiros gerados por recursos extraordinários obtidos do Fundo de Estabilização de Rendas do Cobre.

O FEPC, que seria incialmente temporário (de 2005 até 2006), era marcado por algumas diferenças em relação ao fundo anterior. Foi considerado mais de um mercado relevante para a fixação do PPI (devido ao efeito dos preços dos combustíveis da Costa do Golfo norte-americano verificado em 2005): inicialmente foi levado em conta o preço mais baixo de cada combustível entre três mercados (América, Ásia ou África), mas, posteriormente, foi estabelecida uma média de dois mercados (Costa do Golfo e Costa Atlântica nos EUA). A partir do FEPC, o preço de referência deixou de ser calculado com base na cotação de cada combustível e passou a ser fixado com base no preço do petróleo WTI mais um diferencial de inflação e demais custos de importação. Já a amplitude da banda foi reduzida para $5 \%$ (implicando menor volatilidade) e foram excluídas do FEPC as importações realizadas pela ENAP, cujos subsídios seriam geridos por conta especial da empresa, ocasionando ainda mais pressão financeira sobre a ENAP.

Valero (2010) ressalta que, apesar da tentativa de melhoria, os desafios do FEPC foram semelhantes aos do FEPP: os recursos acumulados não permitiram garantir a viabilidade do fundo (o governo capitalizou o fundo duas vezes em 2008 , em US\$ 200 milhões e US\$ 1 bilhão) e o governo teve de incluir as importações da 
ENAP. Em suma, os recursos foram insuficientes para sustentar o mecanismo em cenários de elevados preços de petróleo, contando com a intervenção do governo e com custo fiscal bastante elevado. O desenvolvimento da política chilena de amortecimento dos preços dos derivados serviu de exemplo para outros países, como Peru e Colômbia.

\section{Fundo de estabilização do Peru}

Antes de estabelecer um fundo de estabilização, o Peru buscou conter a volatilidades dos preços dos derivados a partir da criação de um mecanismo temporário no qual o Imposto Seletivo sobre Consumo (SIC) sobre os combustíveis seria elevado ou reduzido segundo uma média móvel. O mecanismo não funcionou devido à persistência dos altos preços e à redução das receitas fiscais da medida. Assim, surgiu em 2004 o Fundo de Estabilização de Preços dos Combustíveis Derivados de Petróleo.

O fundou foi criado com 60 milhões de soles e incluía gasolina, GLP, querosene, diesel e petróleos industriais. O fundo recebia recursos do orçamento público quando os disponíveis eram insuficientes para pagar aos produtores e aos importadores o desconto dado aos consumidores.

A política peruana é similar à chilena, pois combina o fundo com uma regra de banda de preços ajustada semanalmente pelo Ministério de Minas e Energia do país. Essa banda era definida segundo um preço de referência que se baseava nos preços de paridade de importação e exportação. Enquanto os preços de paridade estivessem dentro da banda seriam transferidos ao público, mas se ultrapassassem os limites máximo e mínimo o subsídio ou a contribuição seria de $100 \%$ da diferença.

O FEPC peruano se caracterizou muito mais por compensar os produtores e importadores do que receber recursos destes, levando à constante intervenção do Estado na transferência de recursos (2005 a 2008). As avaliações do próprio governo permitem concluir que o fundo evitou o repasse da alta volatilidade dos preços internacionais, se contrapondo ao alto custo fiscal que representou para o governo sustentar o mecanismo, deixando claro o trade-off existente. Apesar da similaridade quanto à politica chilena, o Peru não se "aproveitou" da experiência deste e adotou uma regra com base em bandas de preços com ajuste não automático e sujeito à discricionariedade do governo, expondo o mecanismo ao risco moral.

\section{CONCLUSÃO}

$\mathrm{O}$ artigo apontou as graves consequências do controle de preços de combustíveis no Brasil. A defasagem dos preços domésticos do GLP, diesel e gasolina em relação aos preços internacionais foi determinante para a deterioração financeira da empresa nos últimos anos. A perda de receita resultante da defasagem contribuiu para o excessivo endividamento da empresa, o que é particularmente crítico ante as necessidades impostadas pela exploração do pré-sal.

Para atender à demanda crescente do mercado doméstico, a empresa importou 
combustíveis a preços superiores do que pratica domesticamente, com perdas que somaram R \$ 21 bilhões no período de 2011 a 2014. Além das perdas diretas com a importação, a empresa deixou de receber parcela da receita quando o preço doméstico foi inferior à referência internacional. Essa receita perdida foi da ordem de R\$ 98 bilhões. O aumento de endividamento da empresa entre 2011 e 2013 foi equivalente ao valor das perdas até 2014 .

Dada a inviabilidade da liberalização completa dos preços dos derivados, com alinhamento estrito com o preço internacional, uma opção que se coloca para o Brasil é o estabelecimento de fundos de estabilização. A análise de diferentes mecanismos que visam amortecer as oscilações dos preços internacionais dos derivados permite concluir que, apesar de amortecerem a volatilidade dos preços, os mecanismos como os fundos de estabilização mostraram necessidade de injeção de recursos nos diferentes casos analisados. Além disso, ficou claro, nos casos do Chile e do Peru, que a discricionariedade dos governos com relação às bandas de preços era o principal elemento que tornava os fundos inviáveis, já que, no longo prazo, tornava o mecanismo exposto a mudanças externas. Adicionalmente, em cenários de permanência de altos preços dos derivados, semelhante à situação atual, os fundos de estabilização tornam-se sujeitos ao esgotamento de seus recursos.

Em suma, a experiência internacional mostra que existe um trade-off claro entre amortecimento de preços e custo fiscal, principalmente quando se trata de períodos de elevação persistente dos preços internacionais e quando os repasses ou as contribuições feitas aos fundos dependem de uma banda que esteja sujeita a fatores políticos ou à discricionariedade do governo.

Nesse caso, para o Brasil, é essencial que a regra que acompanhe um fundo de estabilização esteja blindada de condicionantes políticos, pois, caso contrário, não trará mudanças efetivas em relação à situação atual. Adicionalmente, deve-se considerar um mecanismo capaz de blindar a configuração de um subsídio, evitando que os custos do desalinhamento hoje sejam simplesmente repassados ao governo.

Como ressaltado ao longo do texto, o mecanismo proposto deve levar em conta tanto a redução da fragilidade financeira da Petrobras, decorrente do desalinhamento dos preços dos derivados domésticos em relação ao internacional, quanto o estímulo à concorrência no downstream da indústria de petróleo no Brasil, segmento este caracterizado pela baixa atratividade aos investimentos privados, não só devido à defasagem de preços, como também devido à imprevisibilidade das mudanças desses preços no país.

Em outras palavras, a política de preços de combustíveis deve ser transparente, visando à redução das incertezas políticas e possibilitando a criação de incentivos ao investimento no segmento de refino.

\section{REFERÊNCIAS BIBLIOGRÁFICAS}

ACCIOLI e MONTEIRO, (2013). Modelo em Xeque. Revista conjuntura econômica fgv: Especial petróleo v. 67. N03, marco 2013. 
ANP (2014). Relatório Mensal de Mercado. Disponível em: www.anp.gov.br Acesso em: 30/03/2014. ANP, (2013). Evolução do Mercado de combustíveis e derivados: 2000-2012. Estudo Temático.

ANP, (2014b). site ANP Anuário Estatístico (vários anos)

ANP. Anuário Estatístico, 2013.

CANADÁ. Natural Resources Canada. Disponível em: http://www.nrcan.gc.ca/energy/fuel-prices/4601 Acesso em: 18 de julho de 2014.

COLOMER, M., TAVARES, A. (2012). Precificação de combustíveis no Brasil e as barreiras ao investimento. Texto para Discussão 004.

EIA, (2014). Dados preços de referência. Disponível em: http://www.eia.gov Acesso em: 30/03/2014.

FECOMBUSTÍVEIS (Federação Nacional do Comércio de Combustíveis e Lubrificantes). (2013) Relatório Anual da Revenda de Combustíveis. 2013. Disponível em: www.fecombustiveis.org.br/. Acesso em: 30/03/2014.

FMI (2013). Energy Subsidy reform: lessons and implication. 28 Jan 2013.

FREDERICO, Giulio; DANIEL, James; BINGHAM, Benedict. (2001) Domestic petroleum price smoothing in developing and transition countries. IMF Working Paper - Fiscal Affairs Department, Maio 2001.

FUNKE, M. (2012). Defasgem no parque do refino estimula importação. Valor Econômico, São Paulo, 25 de setembro de 2012. Disponível em: http://www.valor.com.br/empresas/2842276/defasagem-no-parque-de-refino-estimula-importacao Acesso em: 12 de julho de 2014

GABRIELLI, S. (2012). "Graça Foster foi inábil, diz Gabielli. Entrevisto concedida a SCHÜFFNER, C. Valor Econômico, Rio de Janeiro, 20 de julho de 2012. Disponível em: http://www.valor.com.br/ politica/2758662/graca-foster-foi-inabil-diz-gabrielli Acesso em: 12 de julho de 2014

IISD - International Institute for sustainable development (2010). Lessons learned from Brazil's experience with fossil-fuel subsidies and their reform, 2010. Disponível em: http://www.iisd.org. Acesso em: 26 de março de 2014.

KOJIMA, Masami (2013). Petroleum product pricing and complementary policies: experience of 65 developing countries since 2009. The World Bank — Policy Research Working Paper.

MINISTÉRIO DE MINAS E ENERGIA (2014) Relatório Mensal do Mercado de Combustíveis. Disponível em: www.mme.gov.br.

OMC (1994) Agreement on subsidies and countervailing measures

PETROBRAS, (2014). Relacionamento com os investidores. Disponível em: http://investidorPetrobras. com.br/pt/home.htm Acesso em: 30/03/2014.

REINHART, Carmen; WICKHAM, Peter. (1994) Commodity prices: cyclical weakness or secular decline? IMF: Munich Personal RePEc Archive.

SECEX/MIDIC (Secretaria do Comércio Exterior). (2014) Base de dados aliceweb. 2014. Disponível em: http://aliceweb.desenvolvimento.gov.br/. Acesso em: 30/03/2014.

VALERO, Juan Carlos. (2010) Evaluación económica del fondo de estabilización de precios de los combustibles en Colombia. Dissertação. Universidad Nacional de Colombia.

VALERO, Juan Carlos. (2010) Evaluación económica del fondo de estabilización de precios de los combustibles en Colombia. Dissertação. Universidad Nacional de Colombia.

ZAPATA, Juan Antonio; Rivas, Carlos Gabriel; MELANDRI, Alejandro. (2012) A proposed fuel price stabilization mechanism through the use of financial derivatives. IDB: Infrastructure and Environment Sector. 